\title{
Characterization and erosion of metal-containing carbon films
}

\author{
M. Balden* and C. Adelhelm \\ Max-Planck-Institut für Plasmaphysik, EURATOM Association, D-85748 Garching, Germany
}

PACS: 28.52.Fa, 34.50.Dy, 79.20.Rf, 81.05.Uw

\begin{abstract}
The annealing of magnetron-sputtered carbon films doped with up to 8.5 at $\% \mathrm{~W}, \mathrm{Ti}, \mathrm{V}$, and $\mathrm{Zr}$ prior the erosion experiments led to formation of carbide cyrstallites of several $\mathrm{nm}$. The total erosion yield by 30 and $200 \mathrm{eV} / \mathrm{D}$, impacting as $\mathrm{D}_{3}{ }^{+}$projectiles, at $300 \mathrm{~K}$ and $\sim 750 \mathrm{~K}$ was determined from film thickness changes measured by ion beam analysis. Doping with W, $\mathrm{Ti}, \mathrm{V}$, and $\mathrm{Zr}$ always reduces the total erosion yield by a factor of up to 20 compared to a pure C film. A temperature dependency of the metal erosion was observed. The methane production yield was studied by mass spectrometry. The $\mathrm{CD}_{4}$ production yield decreases less than the total yield or even increases. This implies that the distribution of the chemically eroded species is changed by the dopants. It can be speculated that the re-deposition of carbon is reduced by doping.
\end{abstract}

* Corresponding author address: Dr. Martin Balden, Max-Planck-Institut für Plasmaphysik, Euratom Association, Boltzmannstr. 2, D-85748 Garching, Germany

Tel.: ++49-89-3299 1688, Fax.: ++49-89-3299 1212

Corresponding author e-mail: Martin.Balden @ ipp.mpg.de 


\section{Introduction}

The use of carbon-based material as plasma-facing materials (PFM) in fusion devices caused large progress in the plasma performance and understanding in plasma physics. Nevertheless, carbon is not envisaged as exclusive PFM due to its main drawbacks of large erosion and high tritium retention. Tungsten-based materials are the most promising candidates for PFM in future fusion power plants. For the next step international fusion experimental device, ITER, a combination of $\mathrm{Be}, \mathrm{W}$, and $\mathrm{C}$ is planned as PFM [1]. Beryllium has been used with large success in the European project JET since many years [2]. As is the case for carbon, beryllium is a low-Z material, but additionally, Be getters oxygen and does not show chemical erosion by hydrogen.

Despite this, erosion takes place and the eroded material is re-deposited inside the device on areas hidden for the plasma and on areas subjected to further erosion during the lifetime of the plasma-facing components. The cyclic re-deposition and re-erosion lead to the formation of mixed layers if more than one element is used as PFM.

The planned use of $\mathrm{Be}, \mathrm{W}$, and $\mathrm{C}$ in ITER as well as the present use of $\mathrm{Be}$ and $\mathrm{C}$ in JET $[3,4]$, of W and C in ASDEX Upgrade [5] and of Si-B-Ti-doped fine graphites in EAST [6] increase the interest on the erosion and hydrogen retention behaviour of mixed carbon-metal layers [7].

Previous studies showed a strong reduction of the erosion yield of carbon by hydrogen impact for a few atomic percent bulk doping of $\mathrm{C}$ with $\mathrm{W}$ and also with other dopants $[8,9,10,11]$. Beyond the geometrical shielding of the carbon by the dopants, an effect on the atomistic erosion mechanism is assumed [9]. The observed reduction of the erosion of pure carbon by a Be polluted D plasma is explained by a similar shielding effect [12]. Estimations of the 
M. Balden, C. Adelhelm,

revised Dec. 2006 $11^{\text {th }}$ Intern. Workshop on Plasma-Facing Materials and Components for Fusion Applications, October 11-12, 2006, Max-Planck-Institute for Plasma Physics, Greifswald, Germany

component lifetime as well as tritium retention in co-deposited layers are directly influenced by such reductions of the erosion.

To elucidate the underlying mechanism of the reduction and its variation, laboratory experiments were performed on well characterised carbon films doped with various metals. The selection of dopants was driven by the material selection for ITER and the proposed use of doped graphites in present and future fusion devices, e.g., EAST [6, 13]. Metal-doped carbon films deposited atomically by magnetron-sputtering appear to be the ideal model material for mechanistic investigations on the effect of doping on the erosion of carbon by hydrogen. In a series of investigations these films were characterized and their thermal behaviour was studied $[14,15,16]$.

In our previous erosion investigations, the temperature dependence of the $\mathrm{CD}_{4}$ production yield of doped carbon films was determined for $30 \mathrm{eV}[17,18,19,20]$ and $200 \mathrm{eV}$ deuterium impact [20]. Beside a strong reduction of the maximum in the methane production at elevated temperatures, the $\mathrm{CD}_{4}$ production for $30 \mathrm{eV} / \mathrm{D}$ at room temperature (RT) was increased depending on the concentration of the dopants, W, Ti, V, and Zr. Directly from this fact, two questions arose: i) Is the total erosion yield at RT increased by doping, too? and ii) Is the $\mathrm{CD}_{4}$ emission a good measure for chemical erosion yields? The last question is important because the methane signal is often used as an indicator for the chemical erosion.

Several groups spent a lot of effort to detect and quantify heavier hydrocarbons with mass spectrometry [21, 22, 23], and accurate measurement of methyl radicals and erosion products with high sticking probability remains still challenging $[24,25]$. Therefore, this paper is devoted to simultaneously quantify both, the total erosion yield and the $\mathrm{CD}_{4}$ production yield of well-characterized metal-containing carbon films. The metal concentration of amorphous 
carbon films (a-C:Me) used in the erosion experiments vary between 0 and 8.5 at $\%$ of $\mathrm{W}$, Ti, $\mathrm{V}$, and $\mathrm{Zr}$. The temperature dependence of the chemical erosion was studied for 30 and 200 $\mathrm{eV}$ deuterium impact. The effect of the doping on the distribution of the erosion species is discussed.

\section{Experimental}

\subsection{Film production}

All films, pure carbon ones and those doped with $\mathrm{W}, \mathrm{Ti}, \mathrm{V}$, and $\mathrm{Zr}$, were produced by sputter deposition in a dual source magnetron device. The concentration of the metal was controlled by the power applied to the metal source. A graphite target was used in the second source. No biasing and intentional heating was applied. More details about the deposition process can be found elsewhere [26].

The films were deposited on polished pyrolytic graphite (Grade HPG, Union Carbide) and on silicon single crystals (CrysTec).

\subsection{Film characterisation}

The composition, thickness, lateral and in depth homogeneity, surface morphology, crystallinity, chemical state, and influence of thermal treatment on these properties were characterized. The main investigation techniques were $\mathrm{MeV}$ ion beam analysis (IBA), X-ray diffraction (XRD), X-ray absorption spectroscopy (XAS), and microscopy (scanning electron microscopy / SEM, atomic force microscopy / AFM). These techniques provide information 
on different length scales for the bonding, crystallization, diffusion, and film morphology. More details about the techniques are given in $[14,15,16]$.

\subsection{Erosion experiment}

The erosion of the metal-containing carbon films by hydrogen were studied at the high current ion source in Garching. This source produces a mass-separated monochromatic ion beam [27]. A flux density of $\sim 10^{19} \mathrm{D} / \mathrm{m}^{2} \mathrm{~s}$ was achieved in the $\mathrm{D}_{3}{ }^{+}$beam, which eroded an area of $\sim 0.5 \mathrm{~cm}^{2}$. The ion energies of 90,600 , and $3000 \mathrm{eV}$ per $\mathrm{D}_{3}{ }^{+}$, i.e., 30,200 , and $1000 \mathrm{eV}$ per deuterium atom, respectively, were used, where $1000 \mathrm{eV}$ was only used for normalisation of the $\mathrm{CD}_{4}$ signal.

To investigate the temperature dependence of the erosion, the specimens were heated by electron bombardment from the rear, and the temperature was monitored by an IR-pyrometer. To avoid successive temperature-related changes in the structure of the films, as observed in $[15,16]$, the specimens of all presented data were annealed to $\sim 1100 \mathrm{~K}$ for $\sim 0.25 \mathrm{~h}$ directly before the erosion experiment. Additionally, the set-up was degassed by that annealing and the emissivity of each specimen was determined with a filamentary pyrometer.

The accuracy of the temperature determination was influenced by possible changes of the emissivity during the erosion measurements or by variations in the thermal contacts. These contacts were defined by the screwing connection between specimen and specimen holder and the mechanical contact between the three legs of the transferable holder and the manipulator. Only at the highest temperature, radiation losses could play a role. Overall, the measured temperature for the various specimens at the same heating power varied by less than $\pm 50 \mathrm{~K}$ 
M. Balden, C. Adelhelm,

revised Dec. 2006

compared to the one of an unbombarded pyrolytic graphite specimen. It should be noticed that the temperature difference of two neighbouring steps in a temperature scan (see below) is measured with an accuracy better than $\pm 10 \mathrm{~K}$.

The total erosion yield was determined from the accumulated ion fluence onto the specimen and the total amount of carbon and metal eroded, i.e., the carbon erosion yield is the ratio of eroded $\mathrm{C}$ atoms to impacted $\mathrm{D}$ atoms. These amounts were obtained from $\mathrm{MeV}$ ion beam analyses (IBA) and from in-situ weight-loss (WL) measurements. The uncertainty of the insitu weighing could exceed $\pm 50 \%$ because of the small mass losses and the unknown composition of the eroded material, especially for $200 \mathrm{eV}$ impact.

By restricting the analysing beam to an area of about $1 \times 1 \mathrm{~mm}^{2}$ and scanning the beam across the erosion spot, the depth profile could be evaluated two-dimensionally. This was done for a few erosion spots in detail. For all others, the eroded amount of carbon and metal was extrapolated from two perpendicular line scans. The uncertainty of the eroded carbon amount by IBA is for most films about $\pm 30 \%$, but for films with low erosion it could exceed $\pm 50 \%$. For example, this is the case for the 4 at $\%$ Ti-doped $\mathrm{C}$ film eroded with $30 \mathrm{eV}$ D at RT. The uncertainty of the metal yield is even larger than $50 \%$ because of the small amount of eroded metal.

The methane production yield was obtained from the signal of mass 20 of a quadrupole mass spectrometer (QMS). Several mass signals were recorded during each erosion experiment. The signals without ion beam before and after the erosion experiments (a few times also in between) were linearly interpolated and used for the background correction. Only data of mass 18 and 20 are discussed in this paper. Contributions from the wall due to heating and due to reflected deuterium or ion impact on apertures, as discussed in $[21,23]$, were 
neglected. Deuterated and normal water was disregarded because of the liquid nitrogen cryo pump, which realized a total pressure of $<10^{-6} \mathrm{~Pa}$ without ion beam and of $\leq 10^{-4} \mathrm{~Pa}$ with ion beam. The background-corrected signals were normalized to the ion flux and to the signals from pyrolytic graphite bombarded with $1 \mathrm{keV} / \mathrm{D}$ at $\sim 800 \mathrm{~K}$. At these conditions the chemical erosion yield of graphite is 0.1 [25]. In each measuring campaign the normalization factor obtained from the $1 \mathrm{keV}$ bombardment was determined at least once. This factor varies by less than $\pm 20 \%$, i.e., this is an estimation for the sensitivity variation of the experimental setup over about 1 year of operation and from measurement to measurement. The background subtraction leads to high uncertainty of the data point with low $\mathrm{CD}_{4}$ yield, e.g., at high temperatures in Fig. 1, and slow changes in the composition of the background gas could lead to an increased uncertainty, which may exceed $100 \%$. Nevertheless, the relative accuracy of neighbouring temperatures in temperature scans (see below) is better than $\pm 20 \%$ for the $\mathrm{CD}_{4}$ production yields larger than 0.005 .

Two different fluence scales play a role in the erosion experiments. The first one is correlated with the production of the erosion species, i.e., the hydrogenation of the carbon and the hydrocarbon release have to reach the equilibrium for the particular erosion condition, e.g., after switching the beam on or changing the specimen temperature. The corresponding steady state is reached after fluences less than $10^{22} \mathrm{D} / \mathrm{m}^{2}[17,23,28]$. The second fluence scale is correlated with dopant enrichment at the surface and depends on the dopant particle size and the penetration depth of the eroding species [9]. It should be noticed that the particle size and penetration depth are, with a few $\mathrm{nm}$, of the same order of magnitude for the present investigations.

To avoid strong dopant enrichment, the $\mathrm{CD}_{4}$ production yield, representative of the chemical erosion behaviour, was studied at fluences below $<10^{23} \mathrm{D} / \mathrm{m}^{2}$. The temperature dependence of 
chemical erosion was measured by monitoring continuously the $\mathrm{CD}_{4}$ emission, while the specimen temperature was stepwise increased by controlled power increase from RT to about $1100 \mathrm{~K}$ under continuous deuterium impact (temperature scan). The fluence for each temperature step was kept as small as possible, but large enough to attain nearly equilibrium with constant emission of erosion products at each step. The fluence per temperature step was always below $10^{22} \mathrm{D} / \mathrm{m}^{2}$ and mostly between $4-7 \times 10^{21} \mathrm{D} / \mathrm{m}^{2}$. The accumulated fluence for a complete temperature scan was always below $10^{23} \mathrm{D} / \mathrm{m}^{2}$.

To determine the total erosion yield with sufficient accuracy, i.e., to erode enough material, higher fluences were necessary, which may lead to dopant enrichment. At fixed erosion parameters (temperature, energy), a fluence of $4-9 \times 10^{23} \mathrm{D} / \mathrm{m}^{2}$ was accumulated on the doped films. The $\mathrm{CD}_{4}$ emission was monitored to obtain its fluence dependence and the averaged $\mathrm{CD}_{4}$ production. This averaged chemical erosion is compared with the total erosion yield.

A fresh specimen was transferred into the device for each erosion measurement.

\section{Results and discussion}

\subsection{Composition, nano-crystallinity, and chemical bonding}

All films have a thickness between 0.6 and $1.6 \mu \mathrm{m}$. The total amount of carbon and metal in the films was determined by ion backscattering of $1.5 \mathrm{MeV}$ protons and 0.6 to $4.0 \mathrm{MeV}{ }^{4} \mathrm{He}$ at a scattering angle of $165^{\circ}$. The films contain between 0 and 15 at $\%$ metal, even if only specimens with 8.5 at $\%$ and less were eroded. They show adequate homogeneity of better than $10 \%$ concentration variation across the eroded depths. The oxygen content was always 
below 4 at $\%$. Less than 1 at $\%$ argon was detected in all films, which depended on the metal concentration and which was released by annealing at $1100 \mathrm{~K}$.

The chemical bonding of the metals in the carbon matrix was studied with XAS. All metals in as-deposited films are in carbidic state and, except for $\mathrm{W}$, the atomic order is amorphous [15, 16]. They order on atomic scale by annealing (below $1000 \mathrm{~K}$ ) $[15,16]$. Annealing at higher temperatures leads to growth of nano-crystallites detectable with XRD by width changes of the diffraction peaks $[14,26]$, e.g., at $\sim 1100 \mathrm{~K}$ for $0.25 \mathrm{~h}, 6,3$, and $\sim 2 \mathrm{~nm}$ large carbide grains are formed in 8.5 at $\% \mathrm{~V}, 7$ at $\% \mathrm{Zr}$, and 6 at $\%$ Ti-doped films, respectively. For lower concentrations of these dopants, the diffracted intensity is too low and too strongly widened to be separated from the background. Tungsten forms already $\sim 2 \mathrm{~nm}$ carbide crystallites during the deposition, which do not significantly grow by annealing at $1300 \mathrm{~K}$ [15], even for $\mathrm{W}$ concentration down to 2.8 at $\%$ [26].

\subsection{Temperature dependence of the methane production yield}

Figure 1 summarizes the temperature dependence of the normalized $\mathrm{CD}_{4}$ production yield for $200 \mathrm{eV} / \mathrm{D}$ on different doped films. The maximum in the normalized methane production yield for pure $\mathrm{C}$ films is at about 0.1 [20]. It decreases with increasing dopant concentration, and already 1 at $\% \mathrm{~V}$ doping reduces significantly the produced methane amount. In addition, the maximum in the temperature dependency shifts to lower temperatures with increasing dopant concentration. Such a shift of the maximum by doping was interpreted as a reduction of the activation energy of the hydrogen release $[17,19,29]$. It could be speculated that this activation energy is gradually reduced by the dopants in the $\mathrm{C}$ matrix. 
An example for $30 \mathrm{eV}$ D impact is shown for Zr-doping in Fig. 1, too. Similar data for 30 $\mathrm{eV} / \mathrm{D}$ from other dopants and concentrations are given in $[19,20]$. They also show a reduction at elevated temperature so that the maximum disappears. On the other hand, the $\mathrm{CD}_{4}$ production yield at RT is enhanced by the dopant for $30 \mathrm{eV} / \mathrm{D}[19,20]$. This enhancement shows a concentration dependence [19]. Such an enhancement is also visible in the $200 \mathrm{eV}$ data of Fig. 1, mostly pronounced for Ti-doping. It leads to a minimum - in addition to the maximum - in the temperature dependence of the $\mathrm{CD}_{4}$ production of the 7 at $\%$ Ti-doped film and 8.5 at $\% \mathrm{~V}$-doped film at around $500 \mathrm{~K}$. Even if the variation of the $\mathrm{CD}_{4}$ production for the $\mathrm{V}$-doped one is just at the resolution limit, the time evaluation of the $\mathrm{CD}_{4}$ signal for both, the V-and the Ti-doped film, clearly indicates a behaviour contrary to the temperature scans of all other films. This effect needs further investigations. Nevertheless, this minimum suggests that two different processes are competing with each other around RT. In addition, another competition of at least two other processes takes place at elevated temperatures [29].

For some specimens, the effect of dopant enrichment at the surface due to preferential erosion of the carbon was checked by determining the methane signal once more after measuring the temperature dependence and cooling down. The second data point at RT in Fig. 1 for the 8.5 at $\% \mathrm{~V}$-doped and the 4 at $\%$ Ti-doped film is not significantly increased. So, the enrichment has only a small effect for fluences below $10^{23} \mathrm{D} / \mathrm{m}^{2}$.

\subsection{Total erosion yield and methane production yield}

Figure 2 shows the total erosion yield and the normalized, averaged $\mathrm{CD}_{4}$ production yield of pure and W-doped carbon films for four erosion conditions: 30 and $200 \mathrm{eV}$ deuterium impact in combination with RT and elevated temperature. The accumulated fluences on the doped 
films are $5-7 \times 10^{23} \mathrm{D} / \mathrm{m}^{2}$. It should be mentioned that the elevated temperatures used do not, in general, correspond to those of maximum methane production (Fig. 1 and [20]). The total erosion yields of the pure carbon films are comparable to the published yields from pyrolytic graphite [25]. One has to keep in mind that the total erosion yield includes the physical sputtering, which is negligible for $30 \mathrm{eV} / \mathrm{D}$, but not for $200 \mathrm{eV} / \mathrm{D}$. At $200 \mathrm{eV} / \mathrm{D}$, the physical sputtering yield is about 0.015 for $\mathrm{C}, 0.008$ for $\mathrm{Ti}, 0.007$ for $\mathrm{V}, 0.0005$ for $\mathrm{Zr}$, and negligible for $\mathrm{W}$ [27]. The contribution of the physical sputtering to the total erosion yield is marked for the pure $\mathrm{C}$ in Fig. 2. The estimation of this contribution on the doped films is not possible.

It should be noticed that the integrated $\mathrm{CD}_{4}$ production for the $4 \mathrm{at} \% \mathrm{~W}$-doped $\mathrm{C}$ film at $\mathrm{RT}$ and $200 \mathrm{eV}$ shown in Fig. 2 is higher than the respective data point in Fig. 1, which was measured at a $\sim 10$ times lower fluence. The increased $\mathrm{CD}_{4}$ production could be explained by some dopant enrichment at the surface. This is supported by the time evaluation of the $\mathrm{CD}_{4}$ signal and is in accordance with the concentration dependence reported in [19]. Similar behaviour is observed for the 4 at $\% \mathrm{~V}$ and 2 at $\% \mathrm{Zr}$-doped films, and the missing enhancement for the 4 and 7 at $\%$ Ti-doped ones is in line with the concentration dependence published in [19].

The W-doped C films have a significantly reduced total erosion yield (Fig. 2). The ratio of normalized $\mathrm{CD}_{4}$ production yield to total erosion yield compared to pure $\mathrm{C}$ films changes with the erosion conditions. This ratio $\mathrm{Y}_{\mathrm{QMS}} / \mathrm{Y}_{\mathrm{IBA}}$ for the specimens presented in Fig. 2 and others is plotted in Fig. 3, top, for the four erosion conditions investigated in this work. For pure carbon, $\mathrm{Y}_{\mathrm{QMS}} / \mathrm{Y}_{\mathrm{IBA}}$ is in the range between 0.2 and 0.5 , which is consistent with the reported ratio of heavier hydrocarbon to $\mathrm{CD}_{4}$ measured with QMS ( 1.5-4 for 30 and $\left.200 \mathrm{eV}\right)$ and of the total yield to $\mathrm{CD}_{4}$ ( 8 for $\left.200 \mathrm{eV}\right)$ [21, Roth et al. in 22]. The erosion products could be divided in four groups, which are defined by their observability: i) methane, ii) methyl radical, 
iii) heavier hydrocarbons detectable in the residual gas, and iv) erosion products with high sticking probability at the walls. It should be noticed that $\mathrm{Y}_{\mathrm{QMS}} / \mathrm{Y}_{\mathrm{IBA}}$ equal to 1 means that the contribution of $\mathrm{CD}_{4}$ to the distribution of erosion species is the same as for carbon eroded with $1 \mathrm{keV} \mathrm{D}$ at $\sim 800 \mathrm{~K}$. It is reported that the total erosion yield under these conditions is only around 3 times larger than the methane production yield [22].

For the doped films, $\mathrm{Y}_{\mathrm{QMS}} / \mathrm{Y}_{\mathrm{IBA}}$ is increased up to 5, i.e., is increased by up to a factor of 10 compared to pure $\mathrm{C}$ films. The increase means that the distribution of erosion species is shifted from heavier hydrocarbons and radicals to more $\mathrm{CD}_{4}$ production by doping. The observed factor of 10 is too large to be explained by shifting only the heavier hydrocarbons into the $\mathrm{CD}_{4}$ signal, also the reported erosion products with high sticking probability and methyl radicals have to be reduced [9]. Further information could be gained from the mass 18 signal, an indicator for methyl radicals and heavier hydrocarbons, and its ratio to mass 20 [17]. This ratio is changed by doping, strongly at elevated temperatures and $200 \mathrm{eV}$ and less at $\mathrm{RT}$ and $30 \mathrm{eV}$. It could be speculated that the erosion products responsible for the formation of re-deposited layers are strongly reduced and, therefore, that less re-deposited layers would be formed in fusion devises. More carbon would be pumped out as methane.

Figure 3 shows in addition the total erosion yield (middle) and the $\mathrm{CD}_{4}$ production yield (bottom) of the doped films in relation to those of pure $\mathrm{C}$ films. If the ratio of the total erosion yields is below 1, it is a direct measure for the reduction of the erosion by the doping. The total erosion yield is reduced for several doped films by a factor of 10 . The total erosion yields obtained from the in-situ weight loss measurements agree within $\pm 50 \%$ with those obtained from IBA. 
For some films at $\mathrm{RT}$, the amount of produced $\mathrm{CD}_{4}$ is even larger than for pure carbon (Fig. 2, data above 1 in bottom panel of Fig. 3). But for most of the specimens, the methane production is lowered by doping. Taking only the ratio of $\mathrm{CD}_{4}$ production yield as an indication for the reduction of chemical erosion, this would lead to wrong conclusions. As an example, the $\mathrm{CD}_{4}$ production for the 3 at $\% \mathrm{~W}$-doped $\mathrm{C}$ film eroded with $30 \mathrm{eV} / \mathrm{D}$ at $\mathrm{RT}$ is increased by about $40 \%$ compared to that of $\mathrm{C}$ films, but the total erosion yield is reduced by a factor 7 (Figs. 2 and 3).

The total erosion yield of the metals is obtained from the metal loss. Physical sputtering should be the erosion process, but the metal yields for $200 \mathrm{eV}$ at elevated temperatures are about doubled compared to those at RT. This is unexpected and has to be studied. Nevertheless, the metal yields are always below the physical sputtering yield for the metals at $200 \mathrm{eV}$. At RT the yield is lower by about one order of magnitude, 0.0018, 0.0007, 0.0009, $<0.0001$, and 0.0001 for the 7 at $\% \mathrm{Ti}, 4$ at $\% \mathrm{Ti}, 4$ at $\% \mathrm{~V}, 4$ at $\% \mathrm{~W}$, and 2 at $\% \mathrm{~V}$ doped $\mathrm{C}$ film, respectively. This indicates again that the enrichment of the metal is not completed, even if the erosion craters have depths between $\sim 100$ and $\sim 500 \mathrm{~nm}$. Further more, it has to be kept in mind that changes in the surface morphology were observed, which are very different for the different erosion conditions and dopants (smoothing and roughening). A detailed discussion of the erosion morphology is beyond the scope of this paper.

\section{Summary}

The total and chemical erosion of different metal-doped carbon films were investigated for 30 and $200 \mathrm{eV}$ deuterium impact and temperatures between room temperature and $1100 \mathrm{~K}$. The metal-doped carbon films were produced by magnetron sputtering. The dopants are present as 
M. Balden, C. Adelhelm,

revised Dec. 2006 $11^{\text {th }}$ Intern. Workshop on Plasma-Facing Materials and Components for Fusion Applications, October 11-12, 2006, Max-Planck-Institute for Plasma Physics, Greifswald, Germany

nanometer-sized carbide crystallites $[14,15,16]$. The total erosion yield was determined from changes of film thickness measured by ion beam analysis $\left(\mathrm{Y}_{\mathrm{IBA}}\right)$ and weight-loss measurements, and the $\mathrm{CD}_{4}$ production yield was measured by mass spectrometry ( $\left.\mathrm{Y}_{\mathrm{QMS}}\right)$.

All doped films have a reduced total erosion yield compared to pure carbon. The reductions are higher for $30 \mathrm{eV}$ than for $200 \mathrm{eV}$ and also higher at elevated temperature than at RT. For the accumulated fluences of $4-9 \times 10^{23} \mathrm{D} / \mathrm{m}^{2}$, the ratio of the total erosion yield of the doped films to the total yield of the pure carbon films is in all cases below 0.7 ; in some cases below 0.1 ; the lowest ratio is $\sim 0.05$.

From the comparison of $\mathrm{Y}_{\mathrm{QMS}}$ based only on the $\mathrm{CD}_{4}$ signal to $\mathrm{Y}_{\mathrm{IBA}}$, it could be concluded that the distribution of the erosion species is strongly shifted to an increased production of methane by doping. From the rare determinations of the chemical erosion yield including heavier hydrocarbons or even radicals [21, 22, 23, 24, 25], it could be concluded that for 30 $\mathrm{eV} / \mathrm{D}$ at RT by far the most eroded carbon is released as methane molecules. Further more, the large ratio of $\mathrm{Y}_{\mathrm{QMS}}$ to $\mathrm{Y}_{\mathrm{IBA}}$ supports the conclusion in [25] that a signification fraction of the chemically eroded carbon by low energy D impact at RT is released as hydrocarbons with high sticking probability. Therefore, it could be speculated that doping reduces the formation of re-deposited layers.

The maximum in the temperature dependence of the methane production yield is reduced with increasing dopant concentration and its peak temperature is shifted to lower values. This looks analogous to the decrease of the activation energy of the hydrogen release proposed in [29]. The appearance of a minimum, in addition to the maximum, in the temperature dependence of the $\mathrm{CD}_{4}$ production for $200 \mathrm{eV}$ deuterium impact suggests that an additional process is responsible for the increase of the $\mathrm{CD}_{4}$ production around $\mathrm{RT}$. 
Last but not least, a temperature dependence of the metal yield is observed, which is not explainable in the simple picture of physical sputtering.

\section{Acknowledgement}

We thank A. Weghorn, M. Fußeder, A. Dorner, S. Lindig, E.L. Cochran, and E. Welter, HASYLAB, for technical assistance and J. Roth and W. Jacob for fruitful discussions. Further more, we acknowledge E. de Juan Pardo, I. Quintana, and B. Cieciwa for their contributions to create background knowledge of the film production and characterization. Part of the work has been performed within the framework of the Integrated European Project „ExtreMat“ (contract NMP-CT-2004-500253) with financial support by the European Community. It only reflects the view of the authors, and the European Community is not liable for any use of the information contained therein. The XAS measurements were supported by the European Community - Research Infrastructure Action under the FP6 "Structuring the European Research Area" Programme through the Integrated Infrastructure Initiative "Integrating Activity on Synchrotron and Free Electron Laser Science". 


\section{Figures captions}

Figure 1: Normalized methane production yield of carbon films doped with $\mathrm{W}, \mathrm{Zr}, \mathrm{V}$, and $\mathrm{Ti}$ versus specimen temperature during bombardment with $200 \mathrm{eV} / \mathrm{D}$. The fluence increases with temperature (sequential bombardment) and is always less than $10^{23} \mathrm{D} / \mathrm{m}^{2}$, mostly even less than $5 \times 10^{22} \mathrm{D} / \mathrm{m}^{2}$ at the highest temperature of the temperature scans. For the 8.5 at $\% \mathrm{~V}$ doped and the 4 at $\%$ Ti-doped film, the methane production was measured again at RT after completing the temperature scan, marked with the larger crossed diamond and open circle. One data set for $30 \mathrm{eV} / \mathrm{D}$ is shown, too.

Figure 2: Total erosion yield obtained from IBA and normalized, averaged $\mathrm{CD}_{4}$ production yield (QMS) of pure and W-doped carbon films at 30 and $200 \mathrm{eV}$ deuterium impact. The accumulated fluences on the doped films were $4-9 \times 10^{23} \mathrm{D} / \mathrm{m}^{2}$. For pyrolytic graphite, the total erosion yield at $1000 \mathrm{eV}$ deuterium impact is obtained from weigh-loss [25] and the $\mathrm{CD}_{4}$ production yield, to which all QMS data are normalized, are given, too. The contribution of physical sputtering to the total erosion yield is marked for the pure carbons (blank area). The $30 \mathrm{eV}$ and the $200 \mathrm{eV}$ data were measured on 3 and $4 \mathrm{at} \% \mathrm{~W}$-doped $\mathrm{C}$ films, respectively.

Figure 3: Top: Ratio of the normalized, averaged $\mathrm{CD}_{4}$ production yield to total erosion yield for pure and doped carbon films with different dopant concentration (4 at $\%$ doping: filled symbols). Data of crossed symbols were measured at $620 \mathrm{~K}$, all other at $\sim 750 \mathrm{~K}$. Half-filled circles represent the total erosion yield of pure carbon after subtracting the contribution of the physical sputtering. Middle: Ratio of the total erosion yield of the doped $\mathrm{C}$ film to pure $\mathrm{C}$ film. Bottom: Ratio of the $\mathrm{CD}_{4}$ production yield of the doped $\mathrm{C}$ film to pure $\mathrm{C}$ film. 
M. Balden, C. Adelhelm, revised Dec. 2006 $11^{\text {th }}$ Intern. Workshop on Plasma-Facing Materials and Components for Fusion Applications, October 11-12, 2006, Max-Planck-Institute for Plasma Physics, Greifswald, Germany
19

TIH 38

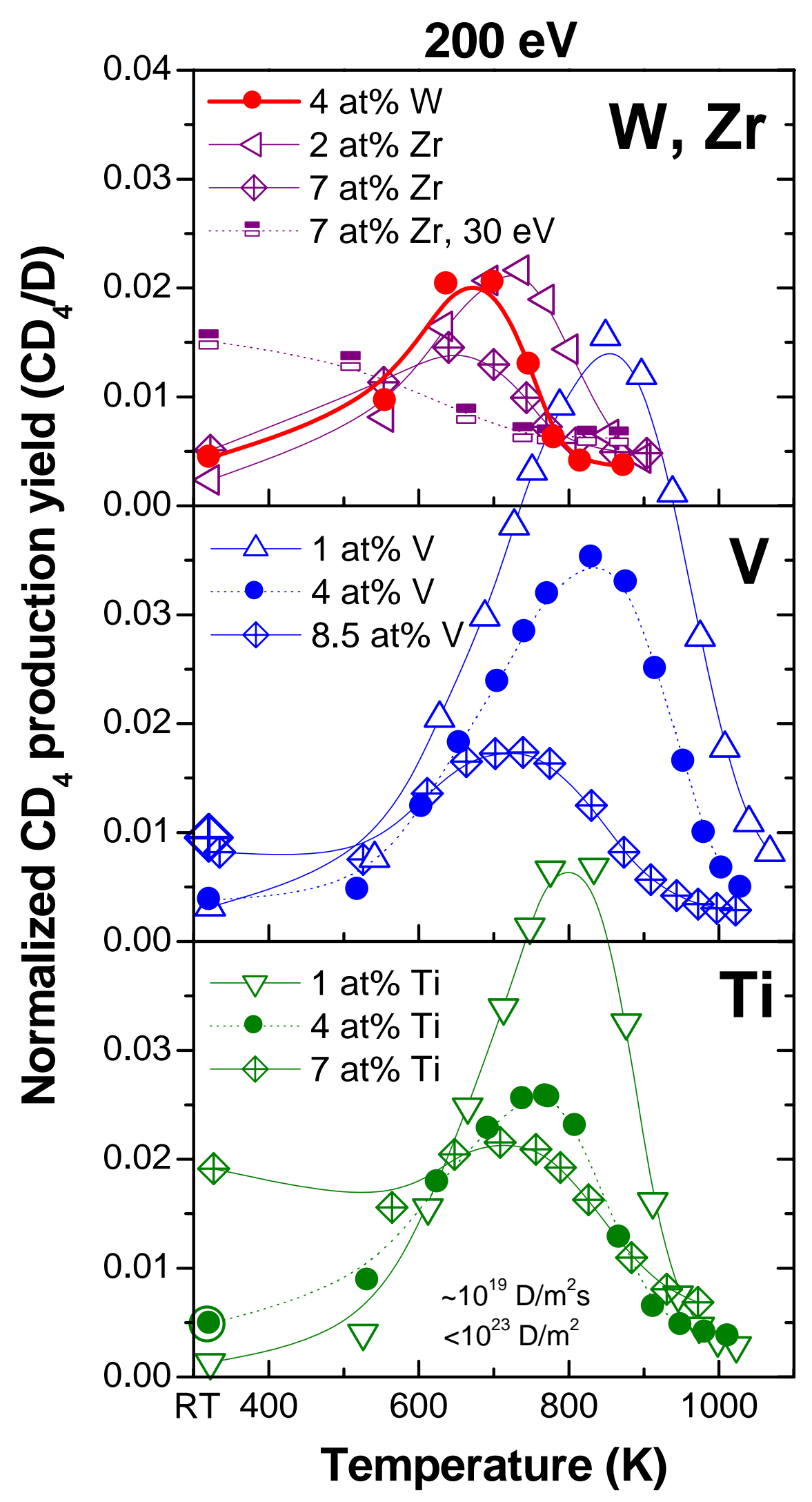

Fig 1 
M. Balden, C. Adelhelm, revised Dec. 2006 $11^{\text {th }}$ Intern. Workshop on Plasma-Facing Materials and Components for Fusion Applications, October 11-12, 2006, Max-Planck-Institute for Plasma Physics, Greifswald, Germany

Pure \& W-doped carbon films

\section{Graphite}

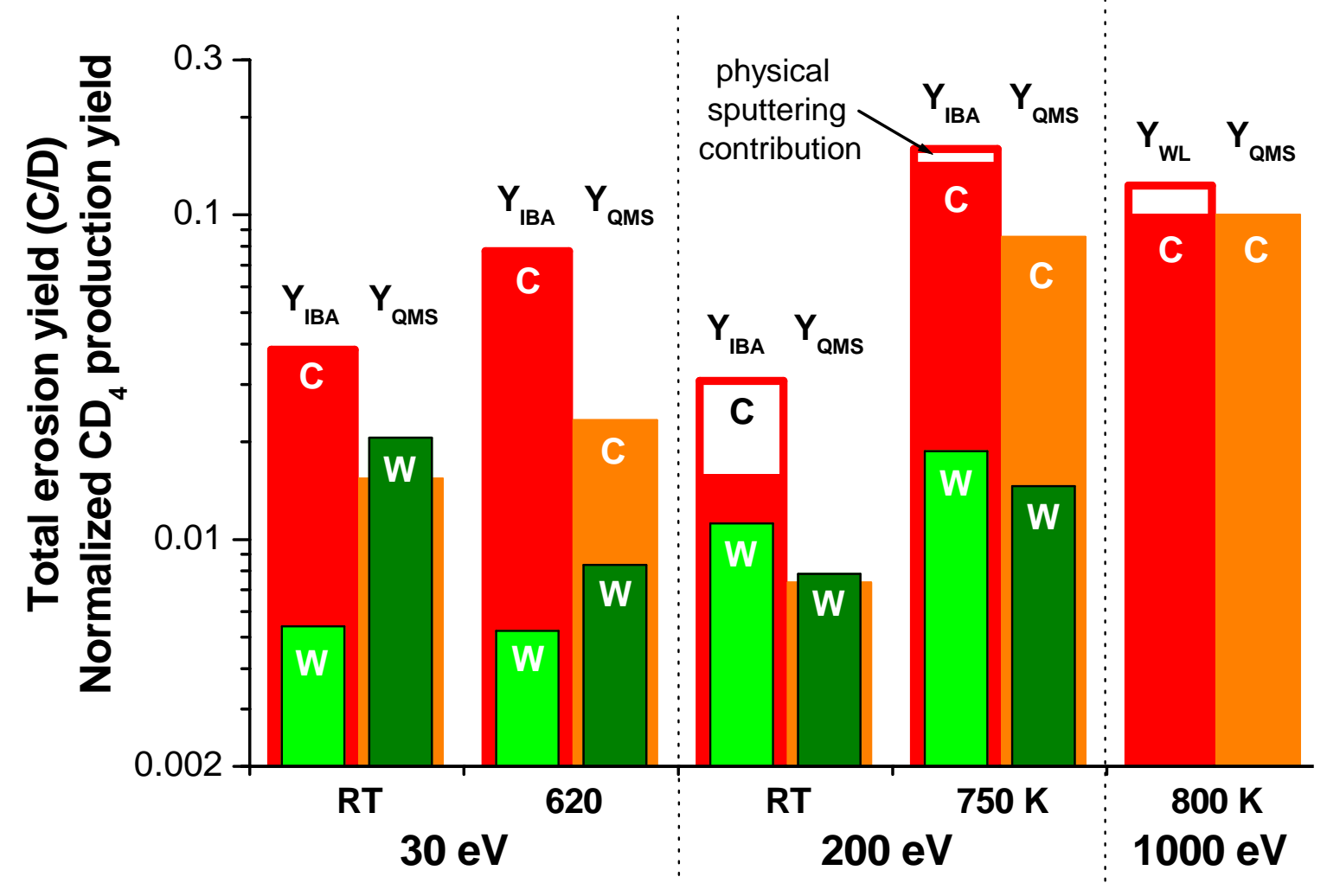

Fig. 2 


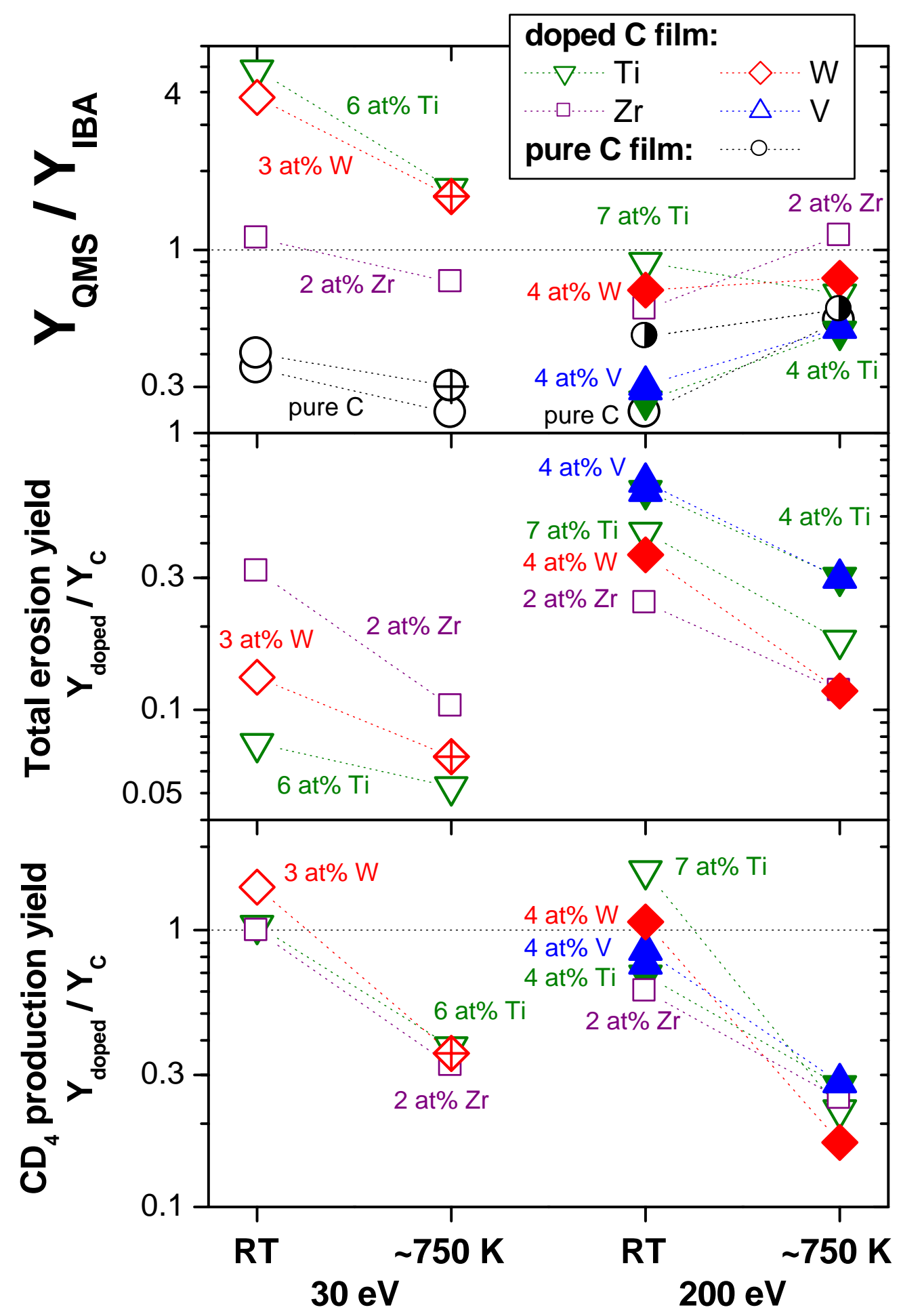

Fig. 3 


\section{References}

[1] Aymar R and International Team 2002 J. Nucl. Mater. 307-311 1

[2] Peacock A T, Coad J P, Lama F, Behrisch R, Martinelli A P, Mills B E, Pick M, Partridge J, Simpson J C B, and Zhu Y K 1990 J. Nucl. Mater. 176-177 326-331

[3] Rubel M, Coad J P, Bekris N, Erents S K, Hole D, Matthews G F, Penzhorn R D, and Contributors to EFDA-JET work programme 2003 J. Nucl. Mater. 313-316 321-326

[4] Likonen J, Vainonen-Ahlgren E, Coad J P, Zilliacus R, Renvall T, Hole D E, Rubel M, Arstila K, Matthews G F, Stamp M, and JET-EFDA Contributors J. Nucl. Mater. 337$33960-64$

[5] Pütterich T, Dux R, Gafert J, Kallenbach A, Neu R, Pugno R, Yoon S W, and ASDEX Upgrade Team 2003 Plasma Phys. Control. Fusion 45 1873-1892

[6] Luo G-N, Zhang X D, Yao D M, Gong X Z, Chen J L, Yang Z S, Li Q, Shi B, and Li J G 2007 Overview of plasma-facing materials and components for EAST Physica Scripta these proceedings, submitted

[7] Federici G, Skinner C H, Brooks J N, Coad J P, Grisolia C, Haasz A A, Hassanein A, Philipps V, Pitcher C S, Roth J, Wampler W R, and Whyte D G 2001 Nucl. Fusion 41 $1967-2137$

[8] Chen A Y, Haasz A A, and Davis J W 1995 J. Nucl. Mater. 22766

[9] Balden M 1999 Physica Scripta T81 64-69

[10] Balden M, García-Rosales C, Behrisch R, Roth J, Paz P, and Etxeberria J $2001 \mathrm{~J}$. Nucl. Mater. 290-293 52-56

[11] Garcia-Rosales C and Balden M 2001 J. Nucl. Mater. 290-293 173-179

[12] Doerner R P, Baldwin M, Hanna J, Linsmeier C, Nishijima D, Pugno R, Roth J, Schmid K, and Wiltner A 2007 Beryllium containing plasma interactions with ITER materials Physica Scripta these proceedings, submitted

[13] Lopez Galilea I, Garcia-Rosales C, Pintsuk G, and Linke L, 2007 Development of finely dispersed $\mathrm{Ti}$ - and $\mathrm{Zr}$-doped isotropic graphites for the divertor of next step fusion devices Physica Scripta these proceedings, submitted

[14] Balden M, Adelhelm C, and Sikora M 2007 Thermal stability and nano structure of metal-doped carbon layers J. Nucl. Mater. at press 
[15] Balden M, Adelhelm C, Köck T, Herrmann A, and Jaimerena-Muga J 2007 Hardness of transition metal doped carbon films and the effect of thermally induced nanostructuring Reviews on Advanced Material Science at press

[16] Adelhelm C, Balden M, and Sikora M 2007 EXAFS investigation of the thermally induced structuring of titanium-doped amorphous carbon films Mater. Sci. Eng. C at press

[17] Balden M, Roth J, de Juan Pardo E, Wiltner A 2003 J. Nucl. Mater. 313-316 348-353

[18] de Juan Pardo E, Balden M, Cieciwa B, Garcia-Rosales C, and Roth J 2004 Physica Scripta T 111 62-67.

[19] Balden M, de Juan Pardo E, Quintana I, Cieciwa B, and Roth J 2005 J. Nucl. Mater. 337-339 980-984.

[20] Balden M, Adelhelm C, de Juan Pardo E, and Roth J 2007 Chemical erosion by deuterium impact on carbon films doped with nanometer-sized carbide crystallites $J$. Nucl. Mater. at press

[21] Mech B V, Haasz A A, and Davis J W 1998 J. Nucl. Mater. 255 153-164.

[22] Haasz A A, Stephens J A, Vietzke E, Eckstein E, Davis J W, and Hirooka Y (eds) 1998 Particle Induced Erosion of Be, C and W in Fusion Plasmas. Part A: Chemical Erosion of Carbon-Based Materials, Atomic and Plasma-Material Interaction Data for Fusion 7 A (IAEA, Vienna)

[23] Meyer F W, Vergara L I, and Krause H F 2006 Physica Scripta T 124 44-49

[24] Vietzke E 2001 J. Nucl. Mater. 290-293 158-161

[25] Balden M and Roth J 2000 J. Nucl. Mater. 280 39-44

[26] Balden M, Cieciwa B T, Quintana I, de Juan Pardo E, Koch F, Sikora M, and Dubiel B 2005 Surf. Coat. Technol. 200 413-417

[27] Eckstein W, Garcia-Rosales C, Roth J, and Ottenberger W 1993 Sputtering Data (Max-Planck-Institut für Plasmaphysik, Garching)

[28] Yamada R, Nakamura K, Sone K, and Saidoh M 1980 J. Nucl. Mater. 95278

[29] Roth J 1999 J. Nucl. Mater. 266-269 51-57 